\title{
Modifications of the sympathetic skin response in workers chronically exposed to lead
}

\section{D.B. Nora ${ }^{1,2,3}$, \\ I. Gomes ${ }^{2,3,4}$, \\ G. Said ${ }^{5}$, \\ F.M. Carvalho ${ }^{6}$ and A. Melo ${ }^{3}$}

\author{
${ }^{1}$ Serviço de Neurologia, Hospital de Clínicas de Porto Alegre, \\ Universidade Federal do Rio Grande do Sul, Porto Alegre, RS, Brasil \\ ${ }^{2}$ Serviço de Neurologia, Hospital São Lucas, Pontifícia Universidade Católica do Rio \\ Grande do Sul, Porto Alegre, RS, Brasil \\ ${ }^{3}$ Divisão de Neurologia e Epidemiologia, Faculdade de Medicina, \\ Universidade Federal da Bahia, Salvador, BA, Brasil \\ ${ }^{4}$ Serviço de Neurofisiologia, Hospital Luterano, Universidade Luterana do Brasil, \\ Porto Alegre, RS, Brasil \\ ${ }^{5}$ Service de Neurologie, Centre Hospitalier Universitaire de Bicêtre, \\ Assistance Publique des Hôpitaux de Paris, Université Paris-Sud, Paris, France \\ ${ }^{6}$ Departamento de Medicina Preventiva, Faculdade de Medicina, \\ Universidade Federal da Bahia, Salvador, BA, Brasil
}

\section{Correspondence}

D.B. Nora

R. São Manoel, 1573/702

90620-110 Porto Alegre, RS

Brasil

Fax: +55-51-3230-2307

E-mail:dbnora@terra.com.br

Research supported by CAPES

Received March 9, 2006

Accepted October 9, 2006

\begin{abstract}
The long-term effects of low-level lead intoxication are not known. The sympathetic skin response (SSR) was evaluated in a group of 60 former workers of a primary lead smelter, located in Santo Amaro, BA, Brazil. The individuals participating in the study were submitted to a clinical-epidemiological evaluation including questions related to potential risk factors for intoxication, complaints related to peripheral nervous system (PNS) involvement, neurological clinical examination, and also to electromyography and nerve conduction studies and SSR evaluation. The sample consisted of 57 men and 3 women aged 34 to 69 years (mean \pm SD: $46.8 \pm 6.9$ ). The neurophysiologic evaluation showed the presence of lumbosacral radiculopathy in one of the individuals (1.7\%), axonal sensorimotor polyneuropathy in 2 $(3.3 \%)$, and carpal tunnel syndrome in $6(10 \%)$. SSR was abnormal or absent in 12 cases, representing $20 \%$ of the sample. More than half of the subjects $(53.3 \%)$ reported a history of acute abdominal pain requiring hospitalization during the period of work at the plant. A history of acute palsy of radial and peroneal nerves was reported by about 16.7 and $8.3 \%$ of the individuals, respectively. Mean SSR amplitude did not differ significantly between patients presenting or not the various characteristics in the current neurological situation, except for diaphoresis. The results suggest that chronic lead intoxication induces PNS damage, particularly affecting unmyelinated small fibers. Further systematic study is needed to more precisely define the role of lead in inducing PNS injury.
\end{abstract}

Key words

- Neuropathy

- Sympathetic skin response

- Lead intoxication

- Peripheral nervous system 


\section{Introduction}

Lead intoxication, or saturnism, can be of environmental or occupational origin. Lead accumulates mainly in the bones and has more intense toxic effect on the nervous system, bone marrow and kidneys (1). The most frequently reported symptoms of acute lead intoxication are gastrointestinal complaints and acute encephalopathy, with confusion, hyperactivity, irritability, and depression (2). The involvement of the peripheral nervous system (PNS) in acute intoxications is described as a purely motor disorder, with a tendency towards the involvement of the radial nerve $(2,3)$.

The long-term effects of low-level lead intoxication are not fully known. It was shown in the 70's that workers with asymptomatic lead intoxication present PNS dysfunctions $(4,5)$. Sensory disturbances are not generally described as important findings, with the presence of minor sensory symptoms and normal neurologic results for all the sensory features (2). However, Murata et al. (6) have suggested that lead can also affect autonomous functions, particularly the sympathetic system, at a subclinical level. Two recent studies have described a frequency of 30 and $49 \%$, respectively, of sensory symptoms in cases of chronic lead intoxication $(3,7)$.

It has been suggested that, differently from acute intoxication cases in which motor abnormalities are observed, sensory and autonomic polyneuropathy are seen in longterm lead intoxication, probably reflecting a direct neurotoxic effect of lead (3). These studies have shown slightly altered distal motor latencies and normal sensory nerve conduction. According to the authors, the relative normality observed was due to the fact that routine conduction studies evaluate the integrity of the fastest-conducting large myelinated fibers, and not of unmyelinated fibers, or $\mathrm{C}$ fibers. The functionality of thin unmyelinated nerve fibers can be evaluated by the sympathetic skin response (SSR), a simple and accurate electrophysiological test $(7,8)$ used to evaluate the reflex activity of sudomotor sympathetic pathways.

Although systematic information on the prevalence of lead intoxication in Brazil is not available, isolated studies and the reportedly high exposure indices suggest it to be high (9). High plumbemia levels were observed among workers of a primary smelter which was in activity in Santo Amaro da Purificação, BA, Brazil, between 1960 and 1996, as well as in children living in the city (10-13). The objective of the present study was to evaluate the SSR in a group of former employees at a lead smelter plant.

\section{Subjects, Material and Methods}

A group of 60 former workers of a primary lead smelter located in Santo Amaro (BA, Brazil) was studied in September 2004. The smelter, a subsidiary of the multinational Peñarroya, was established in Santo Amaro in 1960. In 1987, control of the company was transferred to a national group, and the plant was closed in 1993. While the plant was in activity, there was information about the need for medical care for several employees, in the medical service unit, where chelant medication was available for the emergency treatment of cases of abdominal colic (13). In 1974, Mendes (11) observed that $82 \%$ of the 57 employees, randomly selected, had serum lead levels higher than $70 \mu \mathrm{g} / \mathrm{dL}$. The urine concentration of deltaaminolevulinic acid, a less sensitive indicator of lead intoxication, was above $20 \mathrm{mg} / \mathrm{g}$ creatinine in $35 \%$ of the workers. In 1992 , the Regional Delegacy of Work of the State of Bahia (DRT, in the Portuguese acronym) reported that $20.9 \%$ of the 201 workers presented blood lead levels above the allowed Maximum Biological Indices (14). The DRT technicians observed that $18(81.8 \%)$ of the 23 workers of the synterization sector had plumbemia levels of $60 \mu \mathrm{g} / \mathrm{dL}$. Several of 
these workers presented continuously highblood lead levels, with many recorded values above $100 \mu \mathrm{g} / \mathrm{dL}$. The DRT study also showed that $50 \%$ of the 40 samples of lead concentration in the smelter ambient air, collected in December 1991, exceeded the limit of $100 \mu \mathrm{g} / \mathrm{m}^{3}$ established by the occupational legislation, and the highest level observed was $162 \mu \mathrm{g} / \mathrm{m}^{3}$. An inspection performed by the Worker Health Center similarly reported high lead levels in the ambient air at several sites within the smelter, in samples collected through the second semester of 1991 (14). The $100 \mu \mathrm{g} / \mathrm{m}^{3}$ limit was exceeded in samples collected in the synterization, oven, oven load, mechanical operation, and cleaning sectors. The environmental waste left by the company included about 500,000 tons of residues, containing 2-3\% lead, scattered around the area occupied by the company and around the city itself. Large waste mounds were placed directly on the ground under open skies, threatening the subterranean waters and contaminating the Subaé River which crosses the plant terrain and the urban zone. The city administration used large amounts of this waste to pave many of the streets and public places in Santo Amaro. A thick layer of residues could be found under the street stones, often surrounding the pipes of the domestic water supply system. The many environmental sanitation works performed in the city since 1998 contributed to increase the level of exposure of the population to the waste material, which was below the pavement, and to raise the blood concentration of the metal among the children living in the city (15).

The present study was approved by the University Ethics Committee and the individuals admitted to the study gave written informed consent to participate. All subjects were submitted to a clinical-epidemiological evaluation including questions related to potential risk factors for intoxication, complaints related to PNS involvement, and to neurological clinical examination. After this initial evaluation, the individuals were submitted to electromyography and nerve conduction studies which measured sensory conduction of the median, radial, ulnar, superficial peroneal and sural nerves, motor conduction of the median, radial, ulnar, peroneal, and tibial nerves according to established methods (16), and SSR of the upper and lower limbs.

SSR evaluation was performed under suitable environmental conditions, with surface electrodes placed on the palmar and plantar regions and reference electrodes placed on the distal phalanx of the third and second digits, respectively. A 10-s screen was used for the lower limbs and a 5-s screen was used for the upper limbs, with 200-1000 $\mu \mathrm{V}$ sensitivity and filter settings of 0.1 and $20 \mathrm{kHz}$. Electric stimuli were applied to the contralateral limb, with an intensity of 100 $\mathrm{mA}$ and a duration of $0.2 \mathrm{~ms}$. Five recordings were performed for each limb, with a minimum interval of $30 \mathrm{~s}$ between stimuli. The widest amplitude response and its corresponding latency were used for each limb. The equipment used was Medelec-Synergy, London, UK.

Extremity temperatures were maintained above $32^{\circ} \mathrm{C}$. Electromyographic studies with needles or other neurophysiologic techniques were performed when necessary. Criteria of demyelinating or axonal damage to peripheral nerves established in the literature were employed to evaluate nerve conduction abnormalities (17). SSR was considered to be abnormal when absent or when presenting an amplitude of less than 0.8 and $0.6 \mathrm{mV}$ for the upper and lower limbs, respectively, according to the first percentile for the control population for the age range studied, which consisted of individuals from our laboratory.

Data were analyzed with the SPSS software, version 6. Frequencies, means and standard deviations were described. The chisquare or Fisher exact test, when any of the 
expected values were lower than 5 , was used to evaluate the relationship of possible risk factors and clinical results with SSR abnormalities. The mean amplitudes of SSR for two groups, with and without a specific dichotomous variable, were compared by the non-parametric Mann-Whitney test.

\section{Results}

The sample consisted of 57 men and 3 women aged 34 to 69 years (mean $\pm \mathrm{SD}$ : $46.8 \pm 6.9), 83.3 \%$ of them mulattos and $15.5 \%$ blacks. None of them had collegelevel education, $57.1 \%$ had not concluded elementary education and $7 \%$ were illiterate. They all were residents of Santo Amaro and had worked in the lead smelter plant. The neurophysiologic evaluation showed the presence of lumbosacral radiculopathy in 1 of the individuals (1.7\%), axonal sensorimotor polyneuropathy in $2(3.3 \%)$, and carpal tunnel syndrome (CTS) in 6 (10\%). SSR was abnormal or absent in 12 cases, representing $20 \%$ of the sample. SSR was abnormal in only 1 of the 6 CTS cases, being abnormal also in the lower limbs, and was also abnormal in the 2 cases of polyneuropathy.

Table 1 presents the frequency of potential risk factors for a more severe lead intoxication. Most of the individuals lived in places with unpaved backyards along streets paved with smelter residues. More than half (53.3\%) reported a history of acute abdominal pain, which required hospital admission, when they were working at the plant. A history of acute palsy of radial and peroneal nerves was reported by about 16.7 and $8.3 \%$ of the individuals, respectively. None of the parameters investigated presented a statistically significant relationship with SSR abnormalities.

The main complaint reported, related to the current clinical situation, was paresthesia $(73.3 \%)$, followed by weakness $(65.0 \%)$ and generalized or limb pain (51.7\%) (Table 2). About $45 \%$ of the individuals complained of diaphoresis and $45.6 \%$ of the men reported erectile dysfunction. Clinical examination showed some objective sensory alteration in $48.3 \%$ of the individuals, mild limb muscle subjective feeling of fatigue in $11.7 \%$,

\begin{tabular}{|c|c|c|c|c|c|c|}
\hline \multirow[t]{2}{*}{ Risk factor } & \multirow[t]{2}{*}{$\mathrm{N}(\%)$} & \multicolumn{2}{|c|}{$\begin{array}{l}\text { Frequency of } \\
\text { abnormal SSR }\end{array}$} & \multirow[t]{2}{*}{ PR } & \multirow[t]{2}{*}{$95 \% \mathrm{Cl}$} & \multirow[t]{2}{*}{$\mathrm{P}$} \\
\hline & & $\begin{array}{l}\text { With } \\
\text { risk factor }\end{array}$ & $\begin{array}{l}\text { Without } \\
\text { risk factor }\end{array}$ & & & \\
\hline Unpaved street or backyard & $40(66.7 \%)$ & 30.0 & 15.0 & 2.0 & $0.6-6.3$ & $0.189^{a}$ \\
\hline Paving with smelter waste material & $45(75.0 \%)$ & 22.2 & 13.3 & 1.7 & $0.4-6.8$ & $0.712^{\mathrm{a}}$ \\
\hline House constructed with smelter waste material & $14(23.3 \%)$ & 28.6 & 17.4 & 1.6 & $0.6-4.6$ & $0.448^{a}$ \\
\hline Drinks raw milk & $30(50.0 \%)$ & 16.7 & 23.3 & 0.7 & $0.2-2.0$ & $0.519^{b}$ \\
\hline Manipulates or works with bacteria & $6(10.0 \%)$ & 16.7 & 20.4 & 0.8 & $0.1-5.3$ & $1.000^{\mathrm{a}}$ \\
\hline Manipulates or works with paints or pigments & $12(20.0 \%)$ & 25.0 & 18.8 & 1.3 & $0.4-4.2$ & $0.692^{a}$ \\
\hline Manipulates or works with ceramics & $7(11.7 \%)$ & 28.6 & 18.9 & 1.5 & $0.4-5.5$ & $0.619^{a}$ \\
\hline Uses hair dyes & $5(8.3 \%)$ & 20.0 & 20.0 & 1.0 & $0.2-6.2$ & $1.000^{\mathrm{a}}$ \\
\hline History of acute abdominal pain & $32(53.3 \%)$ & 21.9 & 14.8 & 1.5 & $0.5-4.5$ & $0.488^{b}$ \\
\hline History of acute radial paresis & $10(16.7 \%)$ & 10.0 & 20.8 & 0.5 & $0.1-3.3$ & $0.669^{a}$ \\
\hline History of acute peroneal paresis & $5(8.3 \%)$ & 0.0 & 20.4 & 0.0 & $0.0-5.5$ & $0.572^{b}$ \\
\hline
\end{tabular}

SSR = sympathetic skin response; $\mathrm{PR}=$ prevalence ratio; $95 \% \mathrm{Cl}=$ confidence interval at $95 \%$. None of the parameters investigated presented a statistically significant relationship with SSR abnormalities ( ${ }^{a}$ Fisher exact test; ${ }^{b}$ chi-square test). 
and hyporeflex in $18.3 \%$. None of the clinical variables showed strong association with SSR abnormalities. The mean SSR amplitude was not significantly different when patients presenting or not the various characteristics observed in the current neurological situation were compared, except for diaphoresis. In patients reporting this symptom, mean SSR amplitude in the lower limbs was $1.81 \pm 1.35 \mathrm{mV}$, different from that of individuals not presenting this characteristic who had a mean SSR amplitude of $2.63 \pm 1.56$ (P $=0.048)$.

\section{Discussion}

The present data showed a moderate frequency of abnormal SSR in former workers chronically exposed to lead. Although we had no access to a control group from the same region and undoubtedly not exposed, we believe that the abnormalities observed are compatible with some involvement of the reflex sympathetic sudomotor pathways. The control group analyzed consisted of agematched normal individuals from our Neurophysiology Laboratory in the Hospital de
Clínicas de Porto Alegre, who were used to determine the normal values for amplitude for the first percentile. Using this parameter, none of the individuals in the control group presented abnormal SSR, whereas 20\% of the study group had the abnormality. Except for two patients, who presented neurophysiologic signs of axonal polyneuropathy, sensory and motor nerve conduction was normal in the study sample, showing that the SSR afferent pathway, which includes large fibers, was not affected. Therefore, although the possibility of a central involvement of the autonomous nerve system cannot be excluded, we believe that SSR abnormalities are more probably due to the involvement of peripheral nerve unmyelinated fibers.

We observed a high frequency of sensory complaints, such as paresthesias and limb pain as also reported by Rubens et al. (3). This fact also supports the possibility of involvement of PNS unmyelinated fibers in this population. However, the much higher frequency of complaints in our sample maybe partly related to working interests among the individuals studied. In addition, no association between SSR abnormalities and the vari-

Table 2. Prevalence rate and $95 \%$ confidence interval for abnormal sympathetic skin response according to current neurological evaluation in 60 lead workers, Santo Amaro da Purificação, BA, Brazil, in 2004.

\begin{tabular}{|c|c|c|c|c|c|c|}
\hline \multirow[t]{2}{*}{ Clinical characterisitics } & \multirow[t]{2}{*}{$\mathrm{N}(\%)$} & \multicolumn{2}{|c|}{ Frequency of abnormal SSR } & \multirow[t]{2}{*}{ PR } & \multirow[t]{2}{*}{$95 \% \mathrm{Cl}$} & \multirow[t]{2}{*}{$\mathrm{P}$} \\
\hline & & $\begin{array}{c}\text { With the } \\
\text { characteristic }\end{array}$ & $\begin{array}{l}\text { Without the } \\
\text { characteristic }\end{array}$ & & & \\
\hline $\begin{array}{l}\text { Complaint of generalized or lower limb } \\
\text { weakness }\end{array}$ & $39(65.0 \%)$ & 20.5 & 19.0 & 1.1 & $0.4-3.2$ & $1.000^{\mathrm{a}}$ \\
\hline Complaint of generalized or limb pain & $31(51.7 \%)$ & 22.6 & 17.2 & 1.3 & $0.5-3.7$ & $0.605^{\mathrm{b}}$ \\
\hline Complaint of limb paresthesias & $44(73.3 \%)$ & 22.7 & 12.5 & 1.8 & $0.5-7.4$ & $0.486^{a}$ \\
\hline Complaint of diaphoresis & $27(45.0 \%)$ & 25.9 & 15.2 & 1.7 & $0.6-4.8$ & $0.299^{b}$ \\
\hline Complaint of erectile dysfunction & $26(45.6 \%)$ & 15.4 & 22.6 & 0.7 & $0.2-2.1$ & $0.493^{b}$ \\
\hline $\begin{array}{l}\text { Sensory alteration in extremities } \\
\text { (dysesthesia or hypesthesia) }\end{array}$ & 29 (48.3\%) & 24.1 & 16.1 & 1.5 & $0.5-4.2$ & $0.438^{b}$ \\
\hline $\begin{array}{l}\text { Muscle weakness in lower and/or } \\
\text { upper limbs }\end{array}$ & $7(11.7 \%)$ & 14.3 & 20.8 & 0.7 & $0.1-4.5$ & $1.000^{\mathrm{a}}$ \\
\hline Hyporeflex of lower and/or upper limbs & $11(18.3 \%)$ & 9.1 & 22.4 & 0.4 & $0.1-2.8$ & $0.435^{a}$ \\
\hline
\end{tabular}

$\mathrm{SSR}=$ sympathetic skin response; $\mathrm{PR}=$ prevalence ratio; $95 \% \mathrm{Cl}=$ confidence interval at $95 \%$.

None of the clinical variables showed strong association with SSR abnormalities ( ${ }^{a}$ Fisher exact test; ${ }^{b}$ chisquare test). 
ables related to the clinical situation was observed. Among individuals complaining of pain, paresthesia and diaphoresis and with sensory alterations, the frequency of abnormal SSR was higher, but not statistically significant. Perhaps these associations could be established with a larger sample. No relationship was observed between possible risk factors for a higher lead exposure and increased frequencies of SSR abnormality. It is not possible to conclude, therefore, about any association between higher exposure and higher PNS involvement. It is not known, moreover, if these variables present associations which allow the detection of higher lead intoxication frequencies in this population. On the other hand, among the potential risk factors investigated, there are indications that in the past the individuals composing our sample were exposed to acute lead intoxication, since a high frequency of acute abdominal pain and palsy of motor nerves such as the radial and peroneal nerves were reported. These findings are compatible with situations of acute lead intoxication, as reported in the specialized literature (2).

Among the defined neurophysiologic abnormalities, in the current series two patients presented axonal sensorimotor poly- neuropathy and six patients presented CTS. The patients with polyneuropathy were not diabetic and the etiology of that complication was not defined, although moderate alcohol ingestion on weekends was reported. It was not possible to establish a relationship of this complication with chronic lead intoxication. Large fiber axonal injury was not observed in other studies describing PNS abnormalities related to lead (3). It was not possible to associate CTS with chronic lead intoxication, since CTS is a universally prevalent disease. The prevalence observed in the present study (10\%), however, was slightly higher that that generally reported for males (18).

On the basis of the present results and literature data, we believe that chronic lead intoxication induces PNS damage particularly affecting unmyelinated small fibers. Our results do not represent formal proof, but the evidence is suggestive. A systematic study with quantitative histopathologic evaluation to identify lesions in peripheral nerve small fibers in patients chronically exposed to lead, as compared to non-exposed control individuals, is necessary to more precisely define the role of lead in inducing PNS injury.

\section{References}

1. Moreira FR, Moreira JC. Effects of lead exposure on the human body and health implications. Rev Panam Salud Publica 2004; 15 : 119-129.

2. Dumitru D, Zwarts MJ. Acquired neuropathies. In: Dumitru D, Amato AA, Zwarts MJ (Editors), Electrodiagnostic Medicine. Philadelphia: Hanley \& Belfus; 2002. p 1008-1009.

3. Rubens O, Logina I, Kravale I, Eglite M, Donaghy M. Peripheral neuropathy in chronic occupational inorganic lead exposure: a clinical and electrophysiological study. J Neurol Neurosurg Psychiatry 2001; 71: 200-204.

4. Catton MJ, Harrison MJ, Fullerton PM, Kazantzis G. Subclinical neuropathy in lead workers. Br Med J 1970; 2: 80-82.

5. Seppalainen AM, Hernberg S. Sensitive technique for detecting subclinical lead neuropathy. Br J Ind Med 1972; 29: 443-449.

6. Murata K, Araki S, Yokoyama K, Uchida E, Fujimura Y. Assessment of central, peripheral, and autonomic nervous system functions in lead workers: neuroelectrophysiological studies. Environ Res 1993;
61: 323-336.

7. Hirashima F, Yokota T, Hayashi M. Sympathetic skin response in Parkinson's disease. Acta Neurol Scand 1996; 93: 127-132.

8. Gomes I, Nora DB, Becker J, Ehlers JA, Schwartz IV, Giugliani R, et al. Nerve conduction studies, electromyography and sympathetic skin response in Fabry's disease. J Neurol Sci 2003; 214: 21-25.

9. Cordeiro R, Lima Filho EC, Salgado PE. Neurological disorders in workers with low levels of lead in the blood. I: Peripheral neuropathy. Rev Saude Publica 1996; 30: 248-255.

10. Carvalho FM, Neto AM, Peres MF, Goncalves HR, Guimaraes GC, Amorim CJ, et al. Lead poisoning: Zinc protoporphyrin in blood of children from Santo Amaro da Purificação, Bahia, Brazil. J Pediatr 1996; 72: 295-298.

11. Mendes R. Efeitos da exposição profissional ao chumbo em trabalhadores de duas regiões do Estado da Bahia. Rev Bras Sau Ocup 1974; 2: 37-45.

12. Silvany-Neto AM, Carvalho FM, Tavares TM, Guimaraes GC, Amo- 
rim CJ, Peres MF, et al. Lead poisoning among children of Santo Amaro, Bahia, Brazil in 1980, 1985, and 1992. Bull Pan Am Health Organ 1996; 30: 51-62.

13. Asmus CIRF, Silva AP, Filhote MIF, Camara VM, Rego MPCMA. Avaliação de risco à saúde humana por metais pesados em Santo Amaro da Purificação, Bahia. Relatório UNEP/MS/CGVAM; 2003.

14. SESAB/CESAT. Secretaria de Saúde do Estado da Bahia, Centro de Estudos de Saúde do Trabalhador, Sub-Gerência de Higiene do Trabalho, Relatório de Inspeção No. 03/92; 1992.

15. Carvalho FM, Silvany Neto AM, Tavares TM, Costa AC, Chaves CR, Nascimento LD, et al. Blood lead levels in children and environmen- tal legacy of a lead foundry in Brazil. Rev Panam Salud Publica 2003; 13: 19-23.

16. Dumitru D, Amato A, Zwarts MJ. Nerve conduction studies. In: Dumitru D, Amato AA, Zwarts MJ (Editors), Electrodiagnostic Medicine. Philadelphia: Hanley \& Belfus; 2002. p 159-223.

17. Atroshi I, Gummesson C, Johnsson R, Ornstein E, Ranstam J, Rosen I. Prevalence of carpal tunnel syndrome in a general population. JAMA 1999; 282: 153-158.

18. Nora DB, Becker J, Ehlers JA, Gomes I. Clinical features of 1039 patients with neurophysiological diagnosis of carpal tunnel syndrome. Clin Neurol Neurosurg 2004; 107: 64-69. 